\title{
Multidisciplinary approach to management of postintubation tracheal stenoses
}

\author{
A. Brichet*, C. Verkindre*, J. Dupont ${ }^{\#}$, M.L. Carlier*, J. Darras ${ }^{+}$, A. Wurtz \\ P. Ramon*, C.H. Marquette*
}

Multidisciplinary approach to management of postintubation tracheal stenoses. A. Brichet, C. Verkindre, J. Dupont, M.L. Carlier, J. Darras, A. Wurtz, P. Ramon, C.H. Marquette. (C) ERS Journals Ltd 1999.

ABSTRACT: The optimal management of postintubation tracheal stenosis is not well defined.

A therapeutic algorithm was designed by thoracic surgeons, ear, nose and throat (ENT) surgeons, anaesthetists and pulmonologists. Rigid bronchoscopy with neodymium-yttrium aluminium garnet (Nd-YAG) laser resection or stent implantation (removable stent) was proposed as first-line treatment, depending on the type of stenosis (web-like versus complex stenosis). In patients with web-like stenoses, sleeve resection was proposed when laser treatment (up to three sessions) failed. In patients with complex stenoses, operability was assessed 6 months after stent implantation. If the patient was judged operable, the stent was removed and the patient underwent surgery if the stenosis recurred.

This algorithm was validated prospectively in a series of 32 consecutive patients. Three patients died from severe coexistent illness shortly after the first bronchoscopy. Of the 15 patients with web-like stenosis, laser resection was curative in $10(66 \%)$. Among the 17 patients with complex stenoses, three remained symptom-free after stent removal. Bronchoscopy alone was thus curative in more than one-third of the patients. Six patients underwent surgery, two after failure of laser resection and four after failure of temporary stenting. Surgery was always performed with the patient in good operative condition. Palliative stenting was the definitive treatment in nine cases. Tracheostomy was the definitive solution in two cases.

This approach, including an initial conservative treatment, depending on the type of the stenosis, appears to be applicable to almost all patients and allows secondary surgery to be performed with the patient in good condition. Eur Respir J 1999; 13: 888-893.

\begin{abstract}
* Clinique des Maladies Respiratoires and Service de Chirurgie Thoracique, Hôpital A. Calmette, CHRU de Lille, France. ${ }^{\#}$ Dept d'Anesthésie-Réanimation and ${ }^{+}$Service d'Oto-Rhino-Laryngologie, Hôpital C. Huriez, CHRU de Lille, France.
\end{abstract}

Correspondence: C.H. Marquette Clinique des Maladies Respiratoires Hôpital A. Calmette, CHRU de Lille 59037 Lille cedex France

Fax: 33320445177

Keywords: Bronchoscopy stenoses

stents

surgery tracheal

YAG laser

Received: August 191998

Accepted after revision November 171998

This work was supported by the Comite National contre les Maladies Respiratoires et la Tuberculose and by the friends and family of M. Dubulsson ${ }^{\dagger}$.
Tracheal stenosis may complicate tracheal intubation and/or tracheostomy. The use of low pressure cuffs has reduced by 10 -fold the incidence of postintubation stenoses [1-4]. The management of postintubation tracheal stenoses integrating the roles of open surgery and other forms of treatment is not well defined. Surgical series usually ignore the large number of patients not amenable to surgery, whereas bronchoscopic series exclude those undergoing surgery. Tracheal sleeve resection is the definitive treatment for postintubation tracheal stenoses. Usually the diagnosis is made when the stenosis is severe, so that many patients present with acute respiratory failure requiring emergency bronchoscopic dilatation before curative surgery can be performed [5-10]. Poor general health or unstable coexistent diseases frequently contraindicate surgery, at least temporarily $[5,6]$. Therefore, nonoperative techniques, including bronchoscopic or balloon dilatation, laser resection and stenting have been proposed as alternatives to open surgery $[5,6,11-16]$. Indeed, short, web-like stenoses may be cured by laser resection and gentle dilatation $[6,13]$. Stents are also very helpful for splinting lengthy stenoses. In some cases the patients can remain asymp- tomatic after removal of a stent if the stent has been kept in place for several months $[6,16]$.

Based on previous experience [6] in 58 consecutive cases of postintubation stenoses ( 35 treated with a Dumon stent) and on data from the literature, a multidisciplinary management protocol was proposed integrating both operative and nonoperative strategies.

The present paper reports the prospective validation of this therapeutic algorithm

\section{Material and methods}

\section{Patients}

All patients referred to the hospital for initial treatment of a symptomatic postintubation tracheal stenosis, between November 1994 and April 1997, were eligible for the study. The hospital is a 3,500-bed tertiary referral teaching hospital serving a population of 4.05 million inhabitants. Medical and surgical intensive care units (ICU) in this geographical area receive approximately 15,000 admissions $\cdot \mathrm{yr}^{-1}$. All patients from this area requiring treatment of tracheal stenosis were referred to the hospital during the 
study period. For each patient a complete history was obtained including age, sex, underlying illnesses, indication for ventilatory assistance, duration of endotracheal intubation and/or possible tracheostomy, use of low pressure cuff, time interval between extubation and occurrence of first symptoms indicative of tracheal stenosis, and first diagnosis made by the referring physician (tracheal stenosis versus other diagnoses). In addition, the attending anaesthetist assessed the operative risk on admission using the American Society of Anaesthesiology (ASA) score [17]. The ASA score divides patients into five groups: healthy (class 1), mild-to-moderate systemic disease (class 2 ), severe systemic disease (class 3 ), severe systemic disorders that are already life threatening (class 4), and moribund (class 5).

\section{Disease}

Only patients with symptomatic web-like or complex stenoses (see definition below) were included. Patients with asymptomatic tracheal narrowing, patients with tracheal obstruction due to necrotic pseudomembranes and patients with pseudoglottic stenoses (see definition below) were not included. Stenoses were classified into three categories depending on bronchoscopic findings. Pseudoglottic stenoses were defined as typically "A"-shaped stenoses due to lateral impacted fracture of cartilages in patients with a history of tracheostomy. Web-like stenoses were defined as short segment $(<1 \mathrm{~cm})$, membranous concentric stenoses without damage to the cartilages (fig. 1). All other stenoses, including those with an extensive scar $(\geq 1 \mathrm{~cm})$, circumferential hourglass-like contraction scarring, or malacia were defined as complex stenoses (fig. $1)$.

\section{Therapeutic algorithm}

Initial treatment. Once the stenosis had been identified by fibreoptic bronchoscopy, the patients underwent rigid bronchoscopy. Web-like stenoses were treated according to the muscosal sparing technique described by MентA et al. [13] without further stenting. Briefly, radial incisions in the membranous stenosis were performed by neodymium-yttrium aluminium garnet (Nd-YAG) laser photodissection at the 3 and 9-o'clock positions, followed by gentle dilatation with a rigid bronchoscope (10.5 mm OD). Complex stenoses underwent gentle dilatation a)

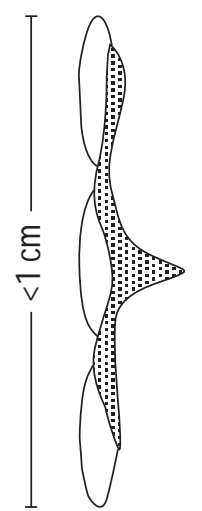

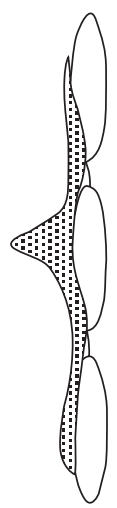

b)

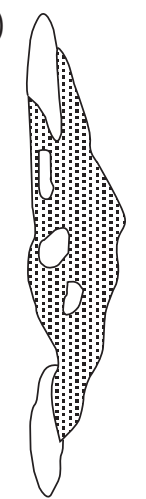

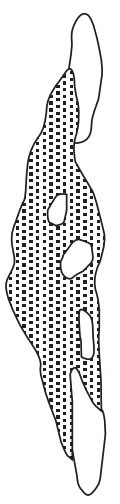

Fig. 1. - Anatomical types of a) web-type and b) complex tracheal stenoses (see text for further definition). with rigid bronchoscopes of increasing size up to 10.5 mm OD. Dilatation was followed immediately by insertion of a Dumon silicone stent (Novatech, Aubagne, France) according to the technique described by DuMON et al. [18]. The stent was selected as short $(\leq 60 \mathrm{~mm}$ length) and as wide ( $\geq 14 \mathrm{~mm}$ OD) as possible. In practice, since submaximal dilatation was deliberately performed using a rigid bronchoscope, the 14- or 16-mm stents usually did not open spontaneously. Complete opening of the stent was obtained by inflating a highpressure balloon inserted into the folded stent. This insertion technique ensured optimal anchoring of the external spikes of the stent in the tracheal wall.

Follow-up. Since a prior study [6] had indicated that recurrence of stenosis after laser resection usually occurs within 1 month of treatment, the patients treated for web-like stenoses were assessed by physical examination and flexible bronchoscopy at 3-week intervals during the first 3 months and every 6 months thereafter. Tracheal stenosis was considered as cured when the patient was free of symptoms, even on exercise, $1 \mathrm{yr}$ after the last therapeutic session. Patients in whom a stent had been implanted were checked by physical examination and flexible bronchoscopy the day after stenting, at 1 month and every 6 months thereafter.

Secondary treatment. In cases of recurrence of symptomatic stenosis in patients with web-like stenosis, a second or possibly a third laser session was performed (up to a total of 3 sessions). In the case of a third recurrence of a symptomatic stenosis the patient was re-evaluated for possible surgery. If unstable coexistent diseases such as coronary heart disease, severe cardiac or respiratory insufficiency or poor general condition were present, a Dumon silicone stent was implanted to splint the stenosis. In the absence of such contraindications, the patient underwent open surgery (fig. 2).

In patients with complex stenoses, once the stent had been in place for 6 months, curative surgery was considered. In the absence of contraindications to surgery, the stent was removed and the patient was followed up closely by flexible bronchoscopy at 3-week intervals. If symptomatic stenosis recurred, surgery was performed. In the other cases close observation was continued during the first 3 months and every 6 months thereafter. If the patient was judged unable to undergo open surgery, the stent was left in place and observation was continued at 6-month intervals (fig. 2).

\section{Data analysis}

Data are presented as meansd values, except where otherwise specified. Fisher's exact test was used to compare categorical variables. For continuous variables the Mann-Whitney test for unpaired series was used. A pvalue $<0.05$ was taken to indicate statistical significance.

\section{Results}

\section{Study population}

Thirty-two consecutive patients (15 web-like stenoses and 17 complex stenoses) entered the study over the 27month study period. Two further patients referred for 


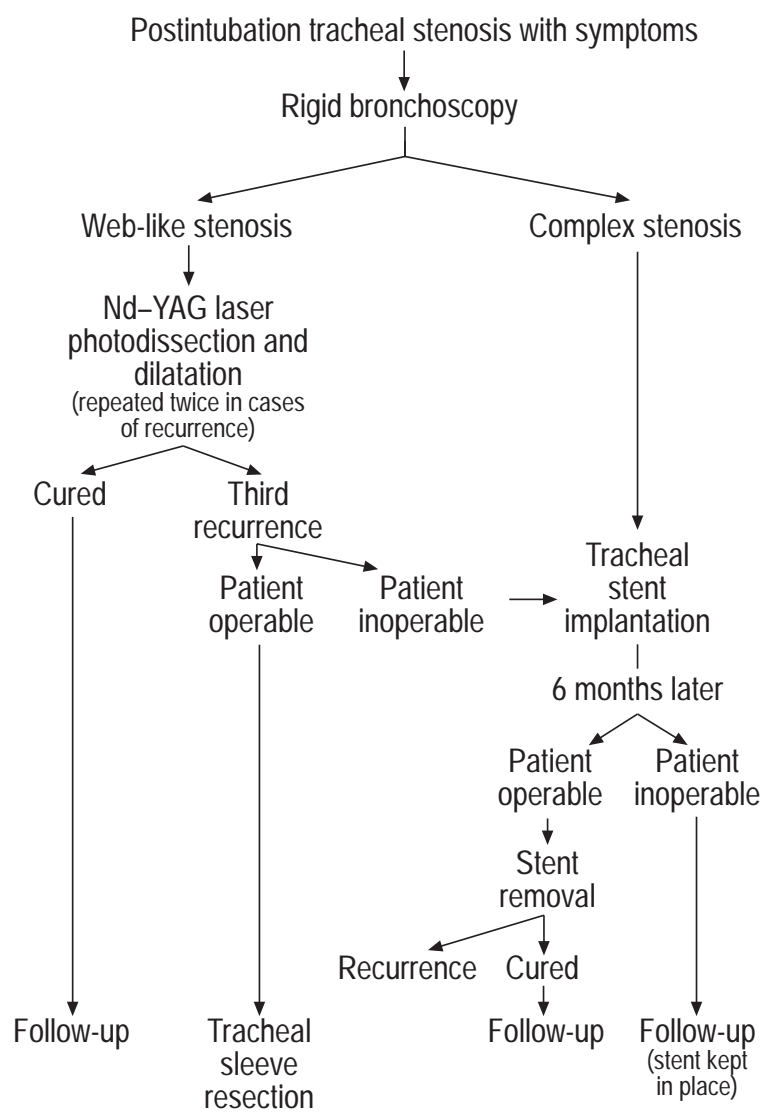

Fig. 2. - Therapeutic algorithm for management of postintubation tracheal stenoses. Nd-YAG: neodymium-yttrium aluminium garnet.

treatment of pseudoglottic stenoses were not included in the study. The estimated frequency of symptomatic postintubation tracheal stenosis in patients admitted to the ICU in the authors' geographical area is approximately one per thousand.

Table 1 shows the baseline characteristics of the study population. The duration of intubation or tracheotomy was $<2$ weeks in more than half of the patients and $<1$ month in $87 \%$. Tracheal stenosis became symptomatic $<6$ weeks after extubation in more than half the patients and $<2$ months after extubation in two-thirds of the patients. Stenosis occurred very late after extubation ( 6 and $18 \mathrm{yrs}$ ) in only two patients. There were no differences in age, sex, coexistent diseases and characteristics of intubation between patients with web-like and patients with complex stenoses. On admission the ASA score was $\geq 3$ in twothirds of the patients. Dyspnoea at rest was noted in 25 patients, 10 of whom had acute respiratory failure with respiratory acidosis. Tracheal stenosis was recognized as the primary cause of respiratory symptoms in 18 of the 32 $(56 \%)$ patients. In the other cases, the first suggested diagnosis was bronchospasm $(n=8)$, worsening of preexisting respiratory insufficiency $(n=3)$, pulmonary emboli $(n=2)$ and retention of respiratory secretions $(n=1)$.

\section{Treatment and outcome}

In practice, there was no difficulty in recognizing the typical anatomical features of web-like, complex and
Table 1. - Characteristics of the study population

\begin{tabular}{lc}
\hline Age yrs & $58 \pm 18(19-83)$ \\
Male/female & $15 / 17$ \\
Cause of initial respiratory failure & $24(75 \%)$ \\
Medical n & 15 \\
Respiratory & 6 \\
Cardiac & 3 \\
Neurological & $8(25 \%)$ \\
Surgical n & 7 \\
Postoperative & 1 \\
Trauma & $24(75 \%)$ \\
Coexistent underlying diseases $n$ & 9 \\
Respiratory insufficiency & 2 \\
Asthma & 5 \\
Cardiac insufficiency & 7 \\
Diabetes & 9 \\
Coronary heart disease & 7 \\
Miscellaneous & $8(25 \%)$ \\
No coexisting diseases $n$ & $12 \pm 10(2-40)$ \\
Details of intubation & $19(59 \%)$ \\
Duration days & $7(22 \%)$ \\
Use of low pressure cuff $n$ & $26 \pm 20(8-70)$ \\
Secondary tracheostomy n & \\
Duration of tracheostomy days &
\end{tabular}

Data are expressed as mean \pm SD (range) or number of patients where indicated (per cent).

pseudoglottic stenoses on the basis of bronchoscopic examination. Very long stenoses were not encountered. The longest stenosis in this series measured approximately $50 \mathrm{~mm}$.

Management of web-like stenoses (15 patients). Six were cured after a single laser session, three after 2 sessions, and one after 3 sessions (fig. 3). In the eight patients who underwent a second laser session, the first recurrence occurred $43 \pm 14$ days (range 21-68) after the first session. In the four patients who underwent a third laser session, the second recurrence occurred $36 \pm 5$ days (range 30-42) after the second session. In three patients laser resection failed after a total of 3 sessions. Thus, as determined by the therapeutic algorithm, they were considered for curative surgery. Two underwent surgery 2.5 and 4 months, respectively, after the first laser session. The remaining patient, judged inoperable owing to unstable coronary heart disease, had a tracheal stent implanted 3 months after the first laser session (figs. 3 and 4). Two patients required tracheostomy 1 month after the first laser session and 6 weeks after the second laser session respectively (fig. 3). The indications for tracheostomy in these two patients were severe respiratory insufficiency requiring home mechanical ventilation and chronic aspiration of oropharyngeal secretions resulting in repeated aspiration pneumonia in a patient with long-term coma respectively.

Management of complex stenoses (17 patients). All had a stent implanted during the first rigid bronchoscopy. In four patients the stent was removed after 6 months, in accordance with the therapeutic algorithm. In two the stenosis did not recur, and the other two underwent surgery (fig. 4). Two additional patients underwent surgery at 6 months after tolerating the stents poorly (table 2; patient Nos. 6 and 8). All the patients who finally 


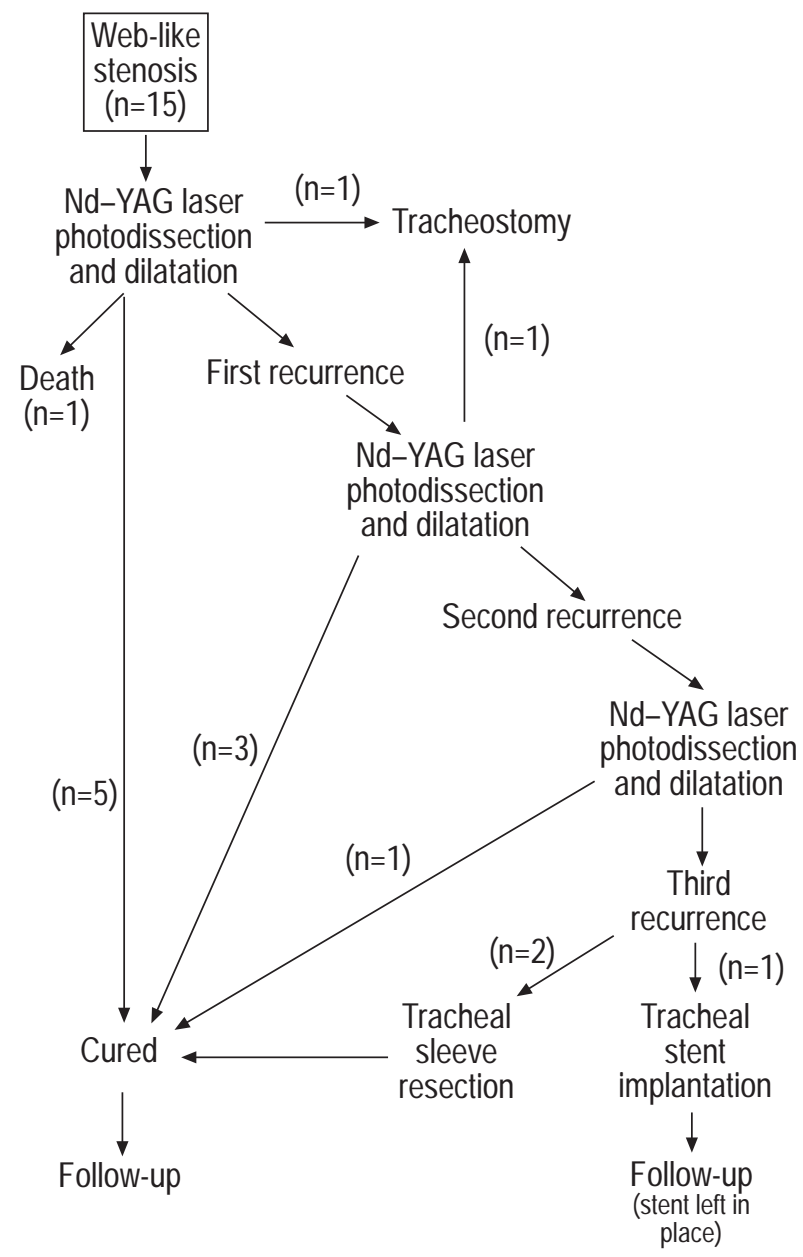

Fig. 3. - Therapeutic management in 15 patients with web-like stenoses. For further explanation of causes of death see text. Nd-YAG: neodymium-yttrium aluminium garnet.

underwent surgery had surgical contraindications at initial presentation: unstable coronary heart disease $(n=$ $2)$, acute pancreatitis $(n=1)$, recent, multiple trauma $(n=$ $1)$, recent stroke $(n=1)$ and toxic coma $(n=1)$. Followup of the 10 patients judged inoperable at six months was $22 \pm 13$ months. Four patients tolerated the stent poorly (table 2; patient Nos. 1, 2, 5 and 7) and two others experienced transient obstruction of their stent (table 2; patient Nos. 3 and 4).

Mortality. There were no peroperative or postoperative deaths related to rigid bronchoscopy or open surgery in this series. The follow-up of the whole series was $28 \pm 13$ months (range 2 weeks -48 months). Three patients died during the follow-up period (peritoneal carcinomatosis 2 weeks after treatment of a web-like stenosis, acute pneumonia complicating severe respiratory insufficiency 3 months after treatment of a complex stenosis and sudden cardiac arrest complicating severe coronary insufficiency 3 months after treatment of a complex stenosis).

Morbidity and outcome. The health status of the study population as assessed by the ASA score clearly improved during the 6 weeks following initial treatment. At

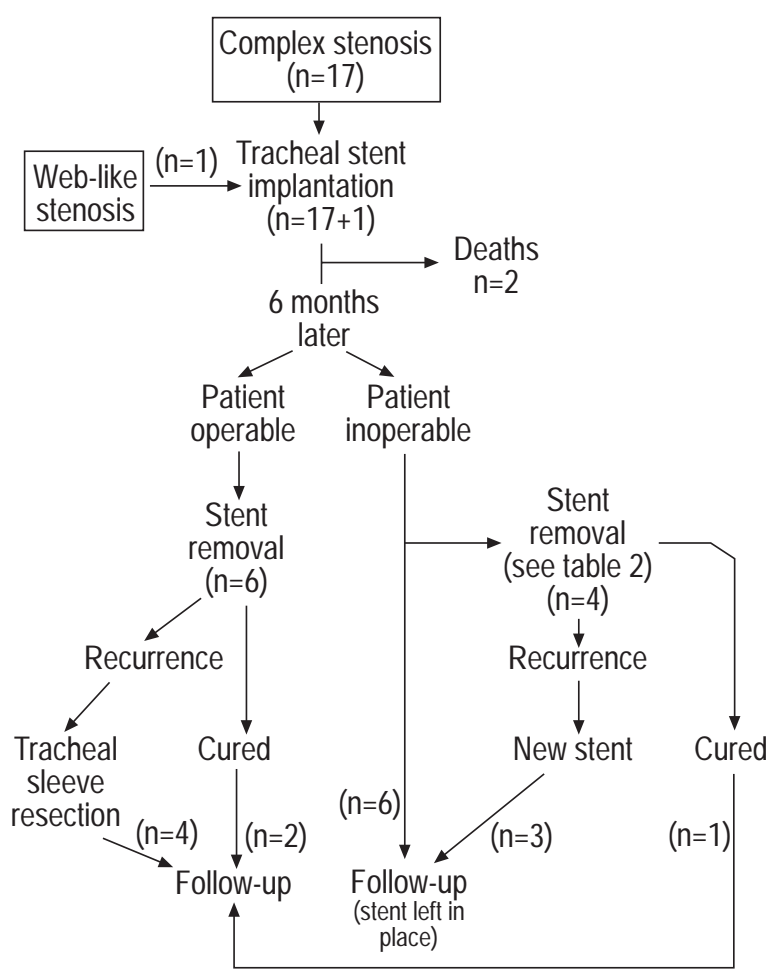

Fig. 4. - Therapeutic management in 17 patients with complex stenoses. For further explanation of causes of death see text.

this point only $14 \%$ of the patients had an ASA score $\geq 3$, as compared with $66 \%$ on admission $(\mathrm{p}<0.05)$.

Even though 25 of the 32 patients were acutely ill on admission, all but one tolerated the initial rigid bronchoscopy well and experienced dramatic improvement of respiratory symptoms. One patient developed acute cardiovascular failure with shock immediately after the induction of anaesthesia. This was an 85-yr-old female with acute respiratory failure, respiratory acidosis and profound dehydration. Although stent implantation was planned (complex stenosis), the procedure had to be interrupted owing to shock shortly after mechanical dilatation. A stent was inserted successfully 3 days later.

There was no treatment-related complication in patients with web-like stenoses. Stent-related complications are shown in table 2.

Two postoperative complications were observed among the six patients who underwent surgery. One patient experienced a very short segmental restenosis at the level of the tracheal suture, which was successfully treated by two laser and dilatation sessions. The second patient developed partial dehiscence of the suture 3 days postoperatively, which resolved spontaneously without further complications

\section{Discussion}

The present study was conducted to clarify the medicalsurgical management of postintubation tracheal stenoses. Local organization of healthcare facilities presented the unique opportunity to validate a therapeutic algorithm in 
Table 2. - Stent-related complications in 18 patients

\begin{tabular}{|c|c|c|c|c|c|}
\hline Pt. No. & Complication & Initial treatment & Outcome & Definitive treatment & Outcome \\
\hline 1 & $\begin{array}{l}\text { Repeated obstruction } \\
\text { by sticky secretions* }\end{array}$ & Removal of the stent & $\begin{array}{l}\text { Severe segmental } \\
\text { malacia }\end{array}$ & \multirow[t]{4}{*}{$\begin{array}{l}\text { Self expandable noncovered } \\
\text { metallic stent }\left(\text { Ultraflex }^{+}\right)\end{array}$} & Well tolerated \\
\hline 2 & $\begin{array}{l}\text { Repeated obstruction } \\
\text { by sticky secretions }\end{array}$ & Removal of the stent & \multirow[t]{3}{*}{$\begin{array}{l}\text { Stenosis } \\
\text { cured }\end{array}$} & & Uneventful \\
\hline 3 & $\begin{array}{l}\text { Obstruction by } \\
\text { sticky secretions }\end{array}$ & $\begin{array}{l}\text { Removal of secretions } \\
\text { (flexible bronchoscope) }\end{array}$ & & & Uneventful \\
\hline 4 & $\begin{array}{l}\text { Obstruction by } \\
\text { sticky secretions }\end{array}$ & $\begin{array}{l}\text { Removal of secretions } \\
\text { (rigid bronchoscope) }\end{array}$ & & & Uneventful \\
\hline 5 & $\begin{array}{l}\text { Repeated obstruction } \\
\text { by sticky secretions }\end{array}$ & Removal of the stent & $\begin{array}{l}\text { Recurrence of the } \\
\text { stenosis }\end{array}$ & New Dumon stent & Well tolerated \\
\hline 6 & Downward migration & Wider Dumon stent & Migration (2nd episode) & Curative surgery & Uneventful \\
\hline 7 & $\begin{array}{l}\text { Downward migration } \\
\text { (twice) }\end{array}$ & $\begin{array}{l}\text { Repositioning of the } \\
\text { stent }\end{array}$ & Migration (3rd episode) & Montgomery T-tube & Well tolerated \\
\hline & $\begin{array}{l}\text { Obstructing granuloma } \\
\text { on the vocal cords }\end{array}$ & & & & \\
\hline 8 & $\begin{array}{l}\text { Obstructing granuloma } \\
\text { on the vocal cords }\end{array}$ & Removal of the stent & $\begin{array}{l}\text { Recurrence of the } \\
\text { stenosis }\end{array}$ & Curative surgery & Uneventful \\
\hline
\end{tabular}

*: All but one of the stent obstructions occurred within the first 3 months. Pt. No.: Patient number. ${ }^{+}$: Boston Scientific Corp, Boston, MA, USA.

all the patients with symptomatic postintubation tracheal stenoses in the local geographical area during the 27month study period. Although it cannot be ascertained how many of the patients admitted to ICUs were intubated, it can be inferred from the data that symptomatic postintubation tracheal stenosis is a very rare complication of intubation (fewer than one per thousand intubated patients).

To minimize complications, curative surgery (tracheal sleeve resection) is proposed only for selected patients in good neurological, cardiovascular and respiratory condition. Accurate preoperative work-up of coexisting conditions and of anatomical features of the stenosis (precise level and length) is essential. To prepare the patients for surgery, repeated mechanical dilatation and/or laser resection is often necessary. For instance, in the largest reported surgical series $71 \%, 53 \%$, and $26 \%$ of patients underwent 1,2 and 3 preoperative rigid bronchoscopies, respectively $[5,10]$. Postoperative mortality, even in selected patients, ranged $1.8-5 \%[5,7,8,10]$. Immediate postoperative complications include cervicomediastinal sepsis, dehiscence of the suture, rupture of the innominate artery, aspiration pneumonia and recurrent laryngeal nerve palsy. When shortand long-term results are taken into account, the failure rate of surgery is about $15 \%[5,8,10]$. In the series of 340 patients reported by BonNETTE et al. [10], 12 died postoperatively and three died later, after failure of the procedure. Definitive cure was obtained at the first attempt in 265 patients, after a second tracheal resection in six patients, after laser resection of granulomas in 20 patients, and after temporary stenting with a Montgomery T-tube in 15 patients. Nineteen patients required tracheostomy or stent implantation.

In very selected cases, bronchoscopy alone can be curative. As shown by Menta et al. [13], diaphragm or weblike stenoses can be treated by the mucosal sparing technique with a $60 \%$ success rate after $1-3$ sessions.

In the remainder of patients (i.e. those who cannot undergo surgery and those with lengthy stenoses), mechanical dilatation alone leads to a recurrence rate of $>90 \%[5$, $6]$. Therefore, splinting the stenosis with a Montgomery T- tube or, even better, with an endotracheal stent is the only solution. The high level of tolerance and the efficacy of the Dumon silicone stent has been extensively documented $[18,19]$. Recently, MarTinez-BALLARIN et al. [16] reported the high efficacy of the Dumon stent in a series of 63 patients with benign tracheobronchial stenoses ( 52 cases of postintubation tracheal stenosis). Stent-related complications included migration in 11 patients $(17.5 \%)$, obstruction in four $(6.3 \%)$, and bulky granuloma formation at the proximal edge of the stent in four $(6.3 \%)$. Migration was managed by reinsertion of the stent in five patients, tracheostomy in two, insertion of a Montgomery T-tube in two and surgery in the remaining two. Granulomas were treated by laser resection in three patients and by insertion of a longer stent in one. Removal of obstructing secretions was achieved by flexible bronchoscopy in two patients and by rigid bronchoscopy in one. The remaining patient died of airway obstruction in another centre, 20 days after stent implantation. This was the only treatment-related death in the series. These figures regarding Dumon stent-related complications are in accordance with the European experience $(5.7 \%$ obstruction and $18.6 \%$ migration) in 263 patients with postintubation tracheal stenoses (J.F. Dumon, Marseilles, France, personal communication) and with the authors' previous experience [6]. Interestingly, a stented tracheal stenosis can progressively mature and stiffen with time so that, once removal of the stent is attempted, a number of patients remain symptom-free. In the series of Martinez-Ballarin et al. [16] the Dumon stent was removed after 18 months in 21 patients without a recurrence of the stenosis in 17 (mean follow-up $259 \pm 173$ days). In a prior retrospective study [6], stent removal was attempted in 11 patients and proved successful in six.

In the present study, the therapeutic algorithm was designed by collaboration between thoracic surgeons, ear, nose and throat surgeons, anaesthetists and pulmonologists. Failure rates, mortality and morbidity of operative and nonoperative techniques in the literature and in the authors' experience [6] were taken into account to establish the therapeutic algorithm. Two additional features were considered when the study design was established. Firstly, 
stenosis can occur relatively soon after ICU discharge $[10$, $20,21]$. In the authors' experience $75 \%$ occurred within 3 months of extubation [6]. During this period severe comorbidity is often present, increasing the risk of postoperative morbidity and mortality. Secondly, clinical signs of tracheal stenosis are insidious and the diagnosis is usually made when the residual tracheal lumen is nearly closed. Thus, as many as $54 \%$ of patients present with acute respiratory failure requiring emergency dilatation [6]. These particular epidemiological features, confirmed in the present study, have two practical consequences. Firstly, the rarity of the disease and its insidious development may result in initial misdiagnosis (the correct diagnosis was initially suggested in only $56 \%$ of the patients). Thus, physicians must be alert to the possibility of tracheal stenosis, even in the presence of atypical respiratory symptoms, whenever there is a recent history of intubation. Secondly, as shown by the evolution of the ASA score, postponing the time of open surgery allows the patient's status to improve significantly. In addition, the fact that three patients died from a severe coexistent illness shortly after initial treatment also emphasizes the need for a conservative approach.

There is no information in the medical or surgical literature regarding the distribution of the anatomical types of postintubation tracheal stenoses. This information is however important since it directly influences the therapy. Of the present 34 consecutive cases, 15 were web-like stenoses, 17 complex stenoses and two pseudoglottic stenoses.

Of the 15 patients with web-like stenoses, laser resection (with gentle dilatation) was curative in $10(66 \%)$. Among the 17 patients with complex stenoses, three remained symptom-free after stent removal. Thus, as a whole, bronchoscopy alone was curative in more than one-third (13) of the patients. Tracheostomy was the definitive solution in two cases and was determined not by difficulties in managing the stenosis but by the severity of the underlying illness. Six patients eventually underwent curative surgery, two after the failure of laser resection and four after failure of temporary stenting. Surgery was always performed with the patient in good operative condition, at least 6 months after the first bronchoscopy. Palliative stenting was the definitive solution in nine cases. Although this study did not include a control group, the results compare favourably with prior results [6] from treating patients without an algorithm approach $(1 \pm 1$ rigid bronchosocopy per patient (range 1-4) versus $3.8 \pm 1.7$ (range $1-4$ ) previously). Stentrelated complications usually presented acutely. Therefore, as has been the authors' practice for $7 \mathrm{yrs}$, all patients with a tracheobronchial stent are given a "stent-holder card". This provides essential information regarding the type, size and location of the stent (in case emergency intubation is necessary), the clinical signs which should alert patients or attending physicians to possible migration or obstruction of the stent, and a means of contacting the bronchoscopy team (24-h hotline).

In conclusion, the multidisciplinary approach, including initial conservative treatment, depending on the type of stenosis, appears to be applicable to almost all patients with postintubation tracheal stenoses. This allows the patients to be prepared safely for possible curative surgery if the initial treatment subsequently fails.

\section{References}

1. Nordin U. The trachea and cuff-induced tracheal injury. An experimental study on causative factors and prevention. Acta Otolaryngol Suppl (Stockh) 1977; 345: 1-71.

2. Heffner JE, Miller KS, Sahn SA. Tracheostomy in the intensive care unit. Chest 1986; 90: 430-436.

3. Stauffer JL, Olson DE, Petty TL. Complications and consequences of endotracheal intubation and tracheotomy: a prospective study in 150 critically ill adult patients. $A m J$ Med 1981; 70: 65-76.

4. Verhulst J, Adjoua RP, Urtazun H. Les complications laryngées et trachéales de l'intubation prolongée. Revue Laryngo 1992; 113: 289-294.

5. Bisson A, Bonnette P, Ben EL, et al. Tracheal sleeve resection for iatrogenic stenoses (subglottic laryngeal and tracheal). J Thorac Cardiovasc Surg 1992; 104: 882-887.

6. Baugnée PE, Marquette CH, Ramon P, Darras J, Wurtz A. Traitement endoscopique des sténoses trachéales postintubation. A propos de 58 cas. Rev Mal Respir 1995; 12: 585-592.

7. Grillo HC, Mathisen DJ. Surgical management of tracheal strictures. Surg Clin North Am 1988; 68: 511-524.

8. Ribet M, Bugnon P, Darras J, Boucquillon P. Chirurgie des sténoses inflammatoires et tumorales de la trachée A propos de 38 cas. Rev Mal Respir 1990; 7: 349-353.

9. Grillo HC, Mathisen DJ, Wain JC. Laryngotracheal reconstruction for subglottic stenosis. Ann Thorac Surg 1992; 53: 54-63.

10. Bonette P, Colchen A, Leroy M, Bisson A. Résection anastomose trachéale pour sténose iatrogène. Une expérience de 340 cas. Rev Mal Respir 1998; 15: 627-632.

11. Dedo HH, Sooy CD. Endoscopic laser repair of posterior glottic, subglottic and tracheal stenosis by division or micro-trapdoor flap. Laryngoscope 1984; 94: 445-450.

12. Shapsay SM, Hybels RL, Beamis JF, Bohigian RK. Endoscopic treatment of subglottic and tracheal stenosis by radial laser incision and dilatation. Ann Otol Rhinol Laryngol 1987; 96: 661-664.

13. Mehta AC, Lee FY, Cordasco EM, Kirby T, Eliachar I, De Boer G. Concentric tracheal and subglottic stenosis. Management using the Nd-YAG laser for mucosal sparing followed by gentle dilatation. Chest 1993; 104: 673-677.

14. Petrou M, Goldstraw P. The management of tracheobronchial obstruction: a review of bronchoscopic techniques. Eur J Cardiothorac Surg 1994; 8: 436-441.

15. Ferretti G, Blanc Jouvan F, Thony F, Pison C, Coulomb M. Benign noninflammatory bronchial stenosis: treatment with balloon dilatation. Radiology 1995; 196: 831-834.

16. Martinez-Ballarin JI, Diaz-Jimenez JP, Castro MJ, Moya JA. Silicone stents in the management of benign tracheobronchial stenoses. Tolerance and early results in 63 patients. Chest 1996; 109: 626-629.

17. Vacanti CJ, Vanhouten RJ, Hill RC. A statistical analysis of the relationship of physical status to postoperative mortality in 68,388 cases. Anesth Analg 1970; 49: 564-566.

18. Dumon JF. A dedicated tracheobronchial stent. Chest 1990; 97: 328-332.

19. Bolliger CT, Probst R, Tschopp K, Soler M, Perruchoud AP. Silicone stents in the management of inoperable tracheobronchial stenoses: indications and limitations. Chest 1993; 104: 1653-1659.

20. Dane TEB, King EG. A prospective study of complications after tracheostomy for assisted ventilation. Chest 1975; 67: 398-404.

21. Attar S, Hankins J, Turney S, Mason JR, Ramirez R, McLaughlin J. Tracheal obstruction. Ann Thorac Surg 1973; 16: 555-567. 